\title{
Design and simulation of an artificial vision sorting machine and cocoa pulping machine
}

\author{
MSc Kelvin Diego Moposita Ortega \\ kelvin.moposita.ortega@alumnos.upm.es \\ https://orcid.org/0000-0002-1032-8558 \\ Universidad Técnica Estatal de Quevedo \\ Quevedo - Ecuador \\ Ing. Miguel Eduardo Albarracín Macías \\ cuartoqbmiguelalbarracin@ hotmail.com \\ Universidad Técnica Estatal de Quevedo \\ Quevedo - Ecuador \\ Ing. Jonathan Daniel Mendoza Acosta \\ dannymen1995@ hotmail.es \\ https://orcid.org/0000-0002-3134-7918 \\ Universidad Técnica Estatal de Quevedo \\ Quevedo - Ecuador
}

\section{RESUMEN}

This research project is focused on the design of an agricultural machine that allows to pulp the cocoa beans quickly and optimally by means of an artificial vision system to classify the beans and to obtain the mentioned product in a shorter production time with optimal quality. Cocoa has been placed in third place in production after sugar and coffee, this is due to the growing demand for chocolate, which is one of the most consumed derivatives in the world. Prior to the design, the manual and traditional methods used on the farms were investigated in order to take a mechanical design alternative. Of the three alternatives proposed, it was decided to take as an example alternative $\mathrm{C}$, using a sieve with a constant translational movement. This machine was designed with the help of SOLIDWORKS software, allowing to obtain plans and dimensions suitable for its construction. A finite element analysis was performed to evaluate its deformations with the loads to which it will be subjected. The design of this machine aims to open new fields in agricultural production and maximize the income of small farmers, taking advantage of the reduction of labor used in the cocoa pulping process.

Keywords: cocoa; machine; depulping process; artificial vision 


\section{Diseño y simulación de una máquina clasificadora por visión artificial y despulpadora de cacao}

\section{RESUMEN}

Este proyecto de investigación está enfocado al diseño de una máquina agrícola que permita despulpar las almendras del cacao de forma rápida y óptima mediante un sistema de visión artificial clasifique las almendras y se pueda obtener el producto mencionado en un menor tiempo de producción con calidad óptima. El cacao se ha situado en el tercer lugar de producción después del azúcar y el café, esto obedece a la creciente demanda por el chocolate, que es uno de sus derivados de mayor consumo en el mundo. Previo al diseño se indagan los métodos manuales y tradicionales ejecutado en las fincas para tomar una alternativa de diseño mecánico, en efecto de las tres alternativas propuestas se decidió tomar como ejemplo la alternativa $\mathrm{C}$ realizado mediante una zaranda con un movimiento traslacional constante. Esta máquina se diseñó con la ayuda del software SOLIDWORKS, permitiendo obtener planos y dimensiones adecuadas para su construcción. En el mismo se pudo realizar un análisis de elementos finitos para evaluar sus deformaciones con las cargas a la que va a estar sometida. El diseño de esta máquina pretende abrir nuevos campos en la producción agrícola y maximizar los ingresos de los pequeños agricultores, aprovechando la reducción de mano de obra empleada en el proceso de despulpado del cacao.

Palabras clave: cacao; máquina, proceso de despulpado; visión artificial

Artículo recibido: 15 enero 2022

Aceptado para publicación: 08 febrero 2022 Correspondencia: kelvin.moposita.ortega@alumnos.upm.es

Conflictos de Interés: Ninguna que declarar 


\section{INTRODUCTION}

The main function of engineering is to facilitate the life of human beings in society, transforming theoretical knowledge into something practical that allows technological advances, making possible the progress of humanity. Currently in Ecuador, the province of Los Rios is one of the main sources of cocoa production that generates economic income for small, medium and large farmers, which has allowed export to other countries thanks to the excellent quality of the product.

Agriculture is one of the sectors where the use of computers used for the control of the final product, weed control, insects is gradually gaining ground. Modern agricultural machinery is equipped with high-performance computing devices, thus achieving greater efficiency in the final production, while achieving less effort on the part of farmers in carrying out their activities. Therefore, it is necessary to use equipment that replaces the traditional function with an automatic one, which presents safety, efficiency, comfort and at the same time is within the economic reach of farmers.

One of the most innovative ways today is the use of Artificial Vision, which is done by means of cameras and specialized software, which can manage and verify that the system works in an optimal way and according to the parameters set by the user. The use of this technology replaces the traditional means of work by new alternatives among which are included automatic control systems that provide greater performance during its operation (Profesional, 2012).

This research work consists of the mechanical design of a prototype of a cocoa pulping machine that incorporates a system that, through the use of artificial vision, helps small, medium and large farmers by speeding up the classification of cocoa. This process will be carried out at the entrance of the product before the pulping process, making the classification of cocoa by extracting the predominant characteristics of each type of product in excellent and bad condition, using the Machine Learning tool incorporated in the Matlab software, in turn, with the use of a pneumatic actuator to reject the unsuitable cocoa (monilla) (Barragan, 2016), allowing the passage of cocoa in excellent condition for subsequent pulping, which will be done by means of a platform that executes an oscillatory movement called pulping sieve. 


\section{Systematization of the problem}

This research focuses on the calculation, design, simulation and selection of mechanical elements for the cocoa sorting and pulping machine, for the respective analysis of the parts that make up the entire mechanism using SolidWorks software, using the FEA finite element method. It is based on the economic analysis that will be elaborated to obtain the manufacturing cost. (Krieger, 2019).

- Is it important to conduct research on the traditional production processes carried out in cocoa companies in the province of Los Ríos?

- What are the most important specifications to be considered for the design of the cocoa grading and pulping machine?

- What type of materials should be used to make the machine?

- What benefits can be gained by performing computer-aided finite element analysis (FEA) in machine design?

- What is the importance of machine vision in agribusiness and what is the most efficient application in agriculture?

- What quality standards will be achieved with the implementation of a cocoa grading system using machine vision?

- How will cocoa farmers benefit from moving from a traditional to an automatic pulping process?

\section{METHODOLOGICAL STRATEGIES OR MATERIALS AND METHODS}

\section{Selection of alternatives}

\section{Alternative A. (Vibratory pulper for almonds)}

This machine was manufactured in Brazil by the company Pinhalense, as can be seen in Figure 1, for the separation of cocoa beans, it has a hopper at the top for the entry of the product. The pulping process is based on the action of the vibratory movement of a hollow mesh as a kind of sieve, into which the product falls. (PINHALENSE, 2018).

Figure 1. Vibratory almond pulping machine

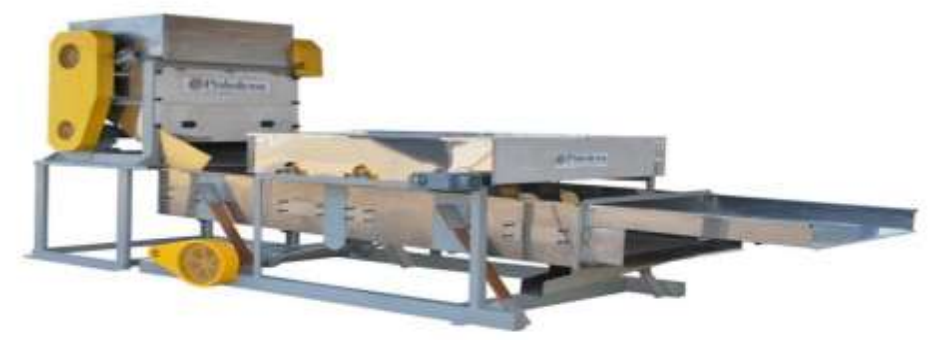




\section{Alternative B. (Horizontal cylinder rotary pulper)}

This machine was designed and built in Ecuador. It executes the cocoa pulping process by means of a hollow cylinder formed by a mesh, as shown in Figure 2, which is driven by a motor. By the effect of the rotational movement, the cocoa beans are detached from the maguey (Guerra, 2017).

Figure 2. Horizontal rotary cylinder pulper

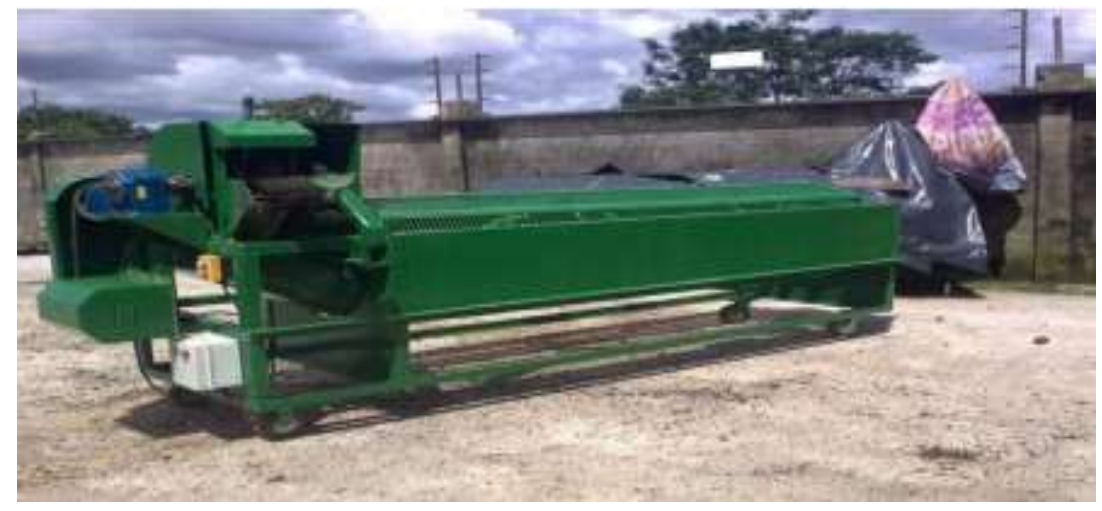

\section{Alternatives C. (Horizontal sieve type pulper)}

This design is characterized by having a platform, which performs a repetitive longitudinal movement, driven by a motor as shown in Figure 3. After the product is deposited on the sieve-type platform, the movement generated causes the almonds to detach and fall to the lower part of the machine where they are collected. Once the cocoa beans are separated, the maguey is driven to the end of the moving platform, where it falls into a container to be collected and transported.

Figure 3. Horizontal shale shaker type pulper

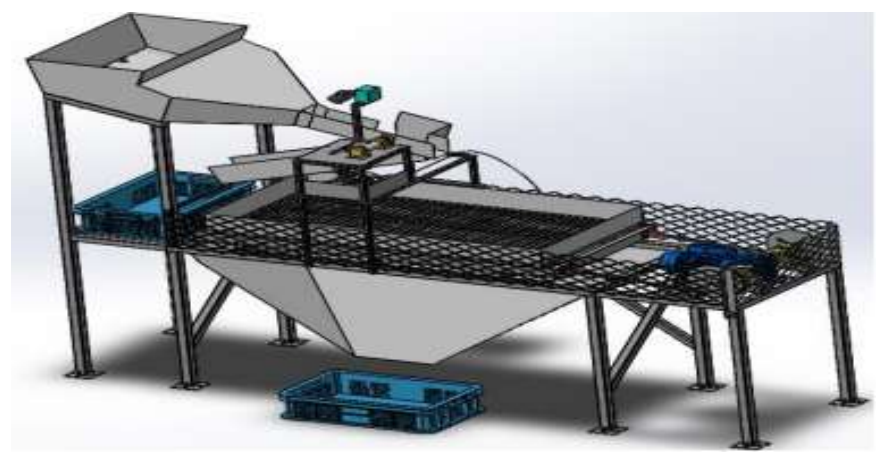

\section{Weighted residuals matrix}

Once the alternatives have been proposed, a weighted residue analysis is carried out to select the best one on which the machine will be designed to extract the beans from the cocoa fruit. 


\section{Weighting criteria}

The evaluation criteria used to select the best alternative are listed below:

Reliability: It is necessary to take into consideration that the machine complies in every aspect with the stated requirements of the process (Nisbett, 2008). Mainly care for the integrity of the seeds and ensure proper separation of the rind and pulp.

Cost: A design is sought that minimizes the production cost of the machine, without affecting its purpose (Norton, 2009).

Maintenance: Easy maintenance and easy replacement of parts and mechanisms should be considered, in order to increase the benefits of the machine and improve its competitiveness.

Easy cleaning: It implies considering a machine that facilitates the cleaning of the parts in contact with the pulp or bark, to ensure the sanitation of the cocoa pulp extraction process during the useful life of the machine (Batista, 2009).

Processing capacity: it must have the capacity to process up to 50 quintals per day.

The following is the weighting of criteria and of each of the alternatives in relation to the criteria used to select the best alternative.

Figure 4. Conclusion of the selection of alternatives

\begin{tabular}{|c|c|c|c|c|c|c|}
\hline Conclusion & Reliability & Cost & $\begin{array}{c}\text { Easy } \\
\text { cleaning }\end{array}$ & Maintenance & $\begin{array}{c}\text { Processing } \\
\text { capacity }\end{array}$ & Total \\
\hline Alternative A & $0.333^{*} 0.3$ & $0.166^{*} 0.3$ & $0.333 * 0.2$ & $0.5 * 0.133$ & $0.166^{*} 0.067$ & 0.2939 \\
\hline Alternative B & $0.166^{*} 0.3$ & $0.416^{*} 0.3$ & $0.166^{*} 0.2$ & $0.166^{*} 0.133$ & $0.333^{*} 0.067$ & 0.2522 \\
\hline Alternative C & $0.5 * 0.3$ & $0.416 * 0.3$ & $0.5 * 0.2$ & $0.333^{*} 0.133$ & $0.5 * 0.067$ & 0.4525 \\
\hline
\end{tabular}

\section{RESULTS AND DISCUSSION}

\section{Calculation of the sieve volume or capacity}

Since this machine is intended for small, medium and large cocoa farmers, it will have a capacity of $96 \mathrm{~kg}$, which is equivalent to a total of 3 tubs of unpulped cocoa.

Data: 3 tubs (unpolished cocoa) $=96 \mathrm{~kg}$ Cocoa density

$$
\begin{aligned}
& \delta=900 \mathrm{~kg} / \mathrm{m}^{3} \\
& V=m \delta \quad \mathrm{V}=96 \mathrm{~kg} 900 \mathrm{~kg} / \mathrm{m} 3 \quad \mathrm{~V}=0,1067 \mathrm{~m} 3
\end{aligned}
$$




\section{Determination of the size of the holes in the perforated plate}

To determine the diameter of the holes of the perforated plate, the measurements of 10 cocoa beans are taken into consideration (Table 1) (Andrade, 2009).

Figure 5. Cross-sectional area of the cocoa bean.

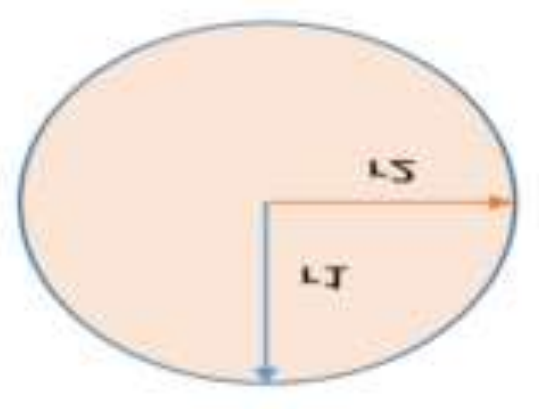

In the Table 1 shows the calculation of the cross-sectional area of 10 cocoa beans, taken as a sample to determine the diameter of the holes in the perforated plate.

Table 1. Average cross-sectional area of cocoa beans.

\begin{tabular}{ccccc}
$\begin{array}{c}\text { Sample } \\
\text { number }\end{array}$ & Width $(\mathbf{m m})$ & Thickness $(\mathbf{m m})$ & $\boldsymbol{\pi} * \boldsymbol{\pi}_{\mathbf{1}} * \boldsymbol{\pi}_{\mathbf{2}}$ & $\begin{array}{c}\text { Cross- } \\
\text { sectional area }\end{array}$ \\
\hline 1 & 12 & 10 & $\pi * 5.5 * 4.5$ & 94.20 \\
\hline 2 & 10 & 9 & $\pi * 5 * 3.5$ & 70.65 \\
\hline 3 & 12 & 10 & $\pi * 5 * 4$ & 94.20 \\
\hline 4 & 9 & 8 & $\pi * 4.5 * 3.5$ & 56.52 \\
\hline 5 & 8 & 10 & $\pi * 4 * 3$ & 62.80 \\
\hline 6 & 10 & 9 & $\pi * 4 * 3.5$ & 70.65 \\
\hline 7 & 9 & 11 & $\pi * 4.5 * 4$ & 77.72 \\
\hline 8 & 10 & 8 & $\pi * 5 * 4$ & 62.80 \\
\hline 9 & 13 & 9 & $\pi * 5.5 * 4.5$ & 91.85 \\
\hline 10 & 12 & 11 & $\pi * 6 * 5.5$ & 103.62 \\
\hline Sum & & & & 785 \\
\hline Average & & & & 78.5 \\
\hline
\end{tabular}

Therefore, by averaging the area of the cocoa beans, we proceed to calculate the diameter of the holes in the plate.

$$
\begin{aligned}
& \mathrm{A}=\pi * d^{2} 4 \\
& \mathrm{~d}=\sqrt{ } \mathrm{A} * 4 \pi \\
& \mathrm{d}=\sqrt{ } 78,5 \mathrm{~mm}^{2} * 4 \pi \\
& d=10 \mathrm{~mm}
\end{aligned}
$$




\section{Simulation of the tray on the screen}

Due to the complexity at the time of analysis in SolidWorks software (Corp, 2017) due to the perforations, the simulation will be performed as a solid pancake without perforations. Figure 6 shows the design of the sieve, in which its "frame will be made of an unalterable and non-deformable material".

Figure 6. Isometric view of the frame and the stainless steel plate of the screen.

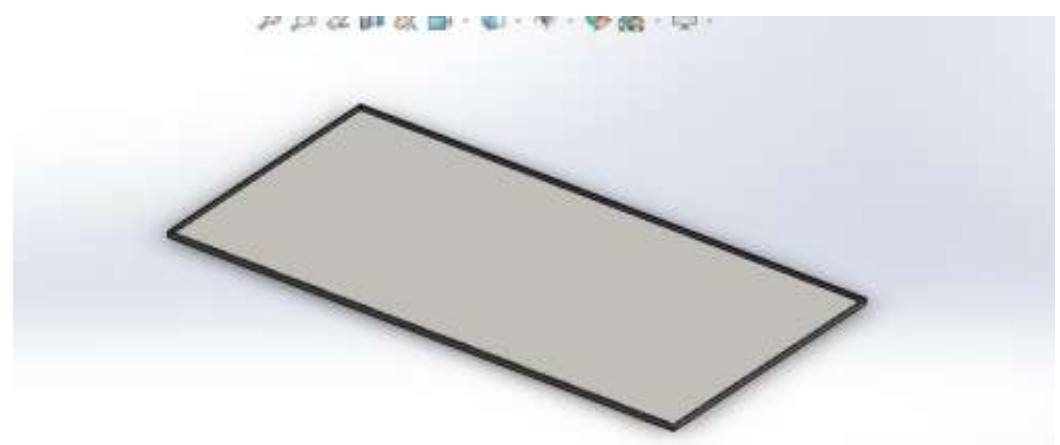

Figure 7. Analysis of the displacements that the steel plate will undergo.

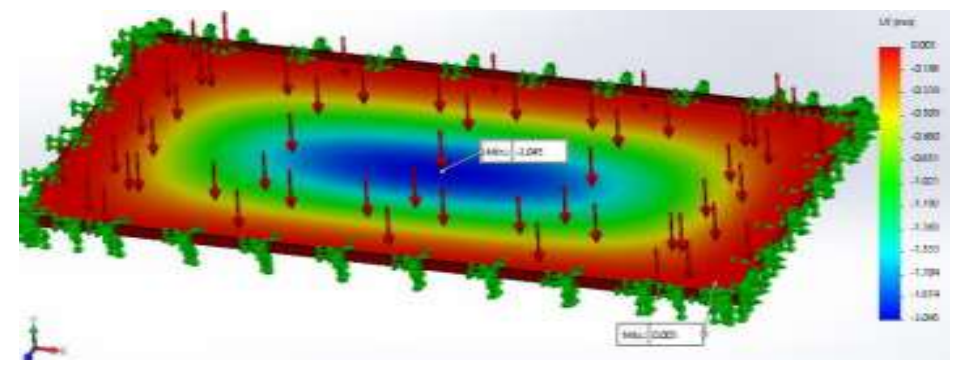

It is worth mentioning that the maximum distributed load that the tray will support is $1.003 \times 10-4 \mathrm{~kg} / \mathrm{mm} 2$, so for the application of the load this value is converted into pressure data, therefore its conversion is $9832.1(\mathrm{MPa})$. The most notorious deformation is found in the $\mathrm{Y}$ axis, with a maximum value of $2.1(\mathrm{~mm})$ located in the center of the sieve, this shows the extreme case which is where most of the cocoa load accumulates. Figure 8. Analysis of the safety factor in stainless steel plate.

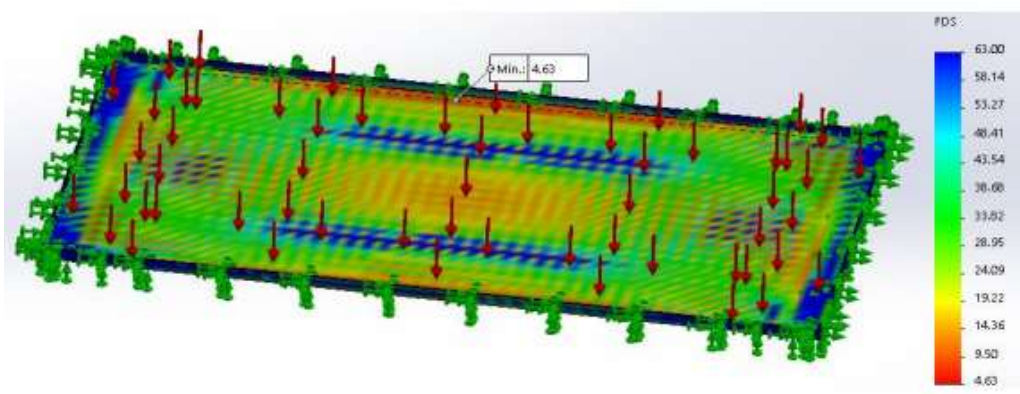

Graph 8 shows the safety factor with which the sieve of the cocoa beans will work, where the maximum and minimum values are indicated. Where the minimum value is within the 
range of 1 to 10 with which it can be verified that using a plate thickness of $1.5 \mathrm{~mm}$. The safety factor is in the range of 4.63 to 63 which will ensure that it will not suffer any inconvenience during the working days guaranteeing that the design will be of optimum reliability.

\section{Structural analysis using SolidWorks}

For the design of the support structure is taken into consideration based on the different calculated parameters of mechanical design, trying to protect the elements and aesthetics of the equipment. To determine if the structure meets the necessary requirements, a simulation is performed using SolidWorks software to perform the finite element analysis.

Table 2. Total weight to be resisted by the structure to be compressed

\begin{tabular}{lcc}
\hline \multicolumn{1}{c}{ FEATURE } & $($ KG $)$ & $(\mathbf{N})$ \\
\hline WEIGHT OF COCOA IN THE SIEVE & 96 & 941.8 \\
\hline WEIGHT OF COCOA IN THE STORAGE HOPPER & 30 & 294.3 \\
\hline WEIGHT OF SCREEN AND SUPPORT & 13 & 127.53 \\
\hline WEIGHT OF THE BRACES & 0.52 & 5.1 \\
\hline WEIGHT OF CONNECTING RODS & 1.24 & 12.16 \\
\hline WEIGHT OF ECCENTRIC DISCS & 6.14 & 60.23 \\
\hline AXLE WEIGHT & 4.26 & 41.8 \\
\hline ENGINE WEIGHT & 11.5 & 112.82 \\
\hline GEARED MOTOR WEIGHT & 31.5 & 309 \\
\hline TOTAL WEIGHT & 194.16 & 1904.7 \\
\hline
\end{tabular}

The weight values were obtained with the help of SolidWorks software. The weight of elements such as pins and bolts is considered negligible since it will not have a major effect on the structure. The material of the structural tube is ASTM A36 steel, for which the maximum admissible slenderness in a bar subjected to compression is equal to $\lambda \leq$ 200 (Marshek, 2013).

Figure 9. Structure for the cocoa pulping machine.

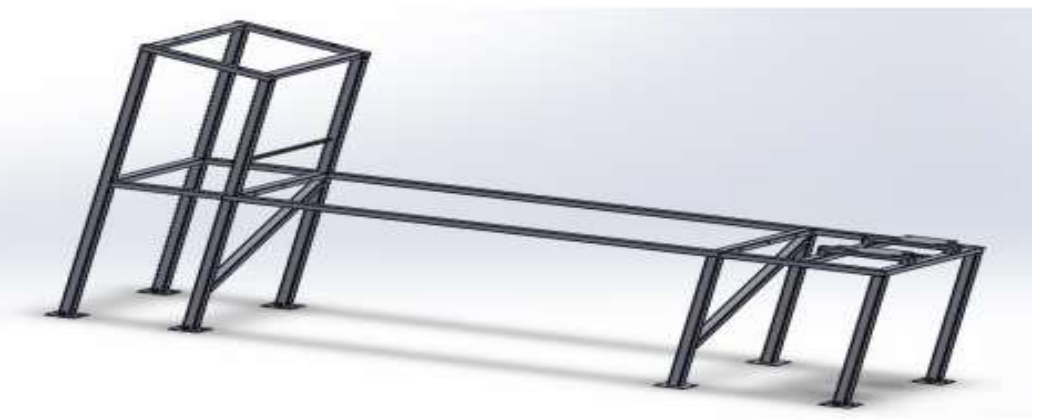


The structure is designed as shown in Figure 9 and ASTM A - 36 steel is chosen as material for the profiles and frames. SolidWorks has the functionality to convert the assigned metallic profiles into linear and nodal elements, in this way, the fixed restriction points of the structure are established, in this case there will be 8 supports that will be fixed on the ground. Consequently, the respective loads to which the structure is subjected are applied. In this case, forces are assigned to the upper part where the unsorted product enters, $568 \mathrm{~N}$, to the part where the pulping sieve is located, $805 \mathrm{~N}$, and finally, to the area where the motor reducer is located, which is equivalent to $588 \mathrm{~N} / \mathrm{m}$.

Figure 10. Location of loads for the analysis in the structure

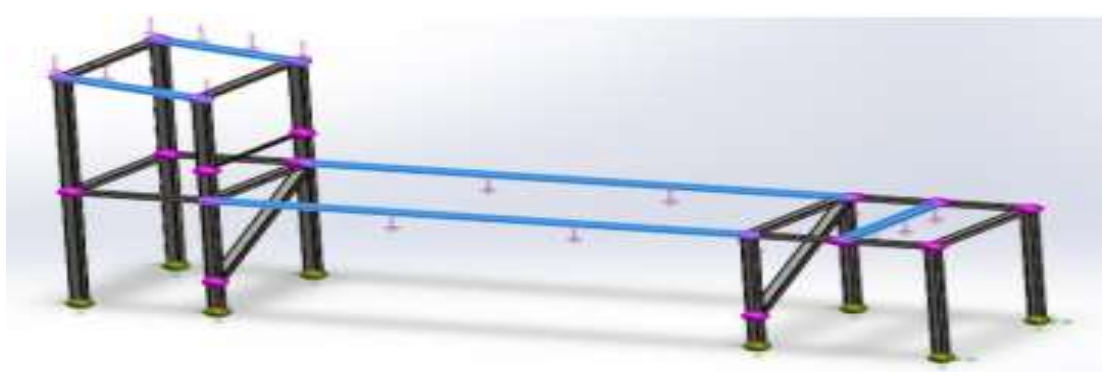

Subsequently, the meshing generated by the software is carried out, which implements the design parameters to record all the restrictions of the structure and finally the results are obtained.

Figure 11. Axial and bending stresses

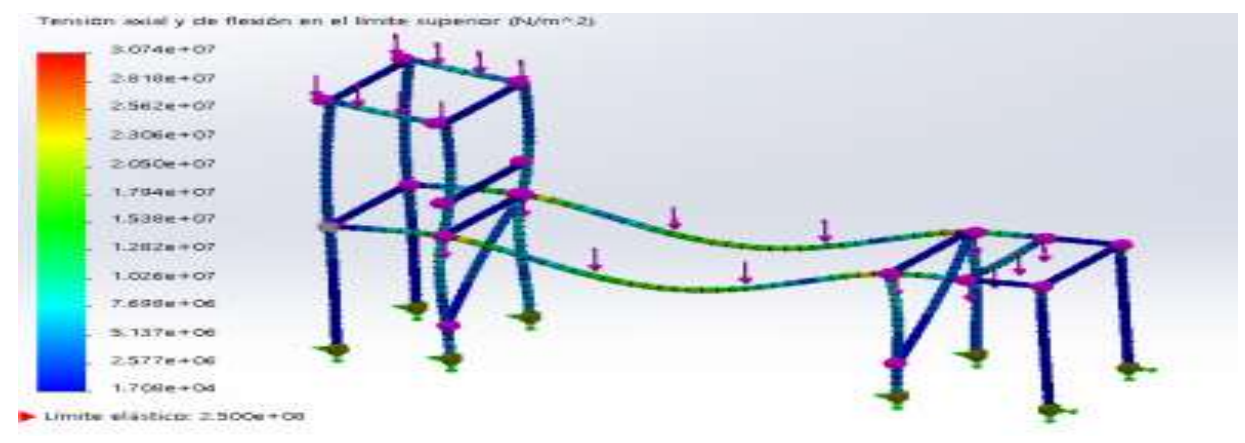

The information obtained through the SolidWorks software, allows to know the value that the material can withstand the axial forces (Y); and the bending subjected on the base of the structure which is where the highest load is concentrated. The elastic limit is $2.5 \times 10^{\wedge} 8$ $\mathrm{N} / \mathrm{m}^{\wedge} 2$, the maximum value is $3.074 \times 10^{\wedge} 7 \mathrm{~N} / \mathrm{m}^{\wedge} 2$ and the minimum value is $1.708 \times 10^{\wedge} 4$ $\mathrm{N} / \mathrm{m}^{\wedge} 2$, these values do not exceed the established elastic limit, so it can be considered that the structural frame will support the static loads complying with a high safety factor. 
Figure 12. Scale of deformation in the structure
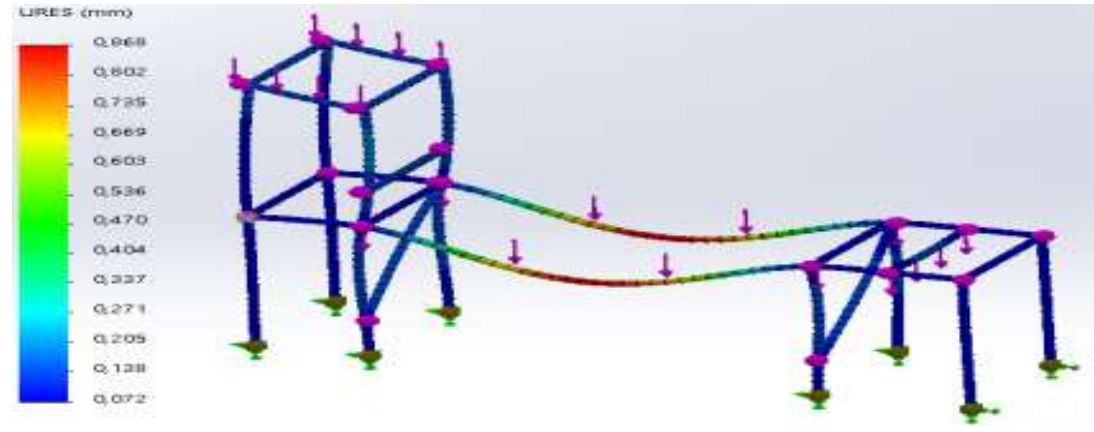

The maximum deformation value is $0.868 \mathrm{~mm}$, and the minimum deformation value is $0.072 \mathrm{~mm}$, this implies that the maximum deformation of the material is less than $1 \mathrm{~mm}$, so it can be established that it will not present a deformation that affects the integrity of the profiles.

\section{Development of the algorithm for cocoa classification}

The development of the cocoa classification system has gone through several phases described below, where the product recognition algorithm is shaped using Matlab software (mathworks, 2018), the instruments used in the cocoa grading system are also mentioned.

\section{System components}

For the development of the system, MathWorks Matlab software was selected, due to its Toolbox focused on acquisition, image processing and Machine Learning, which was very useful for the development of the project. To install the components it is necessary to have the following software, drives and components described below:

- Matlab

- Arduino I/O (Matlab library for Arduino)

- Solenoid valve

- Circuit breaker
- Arduino Driver (Arduino, 2018)

- Arduino board

- Relay

- Pneumatic Piston

After installing the drivers and the required software, we proceed to make the different connections such as the solenoid valve to the pneumatic piston, circuit breaker, relay, digital inputs and outputs of the Arduino board. To install the pneumatic piston, the air hoses coming from the solenoid valve are connected, for this in turn the air is supplied by means of a compressor that will be connected to the solenoid valve as shown in the following graphic. 
Figure 13. Artificial Vision Classification System Components

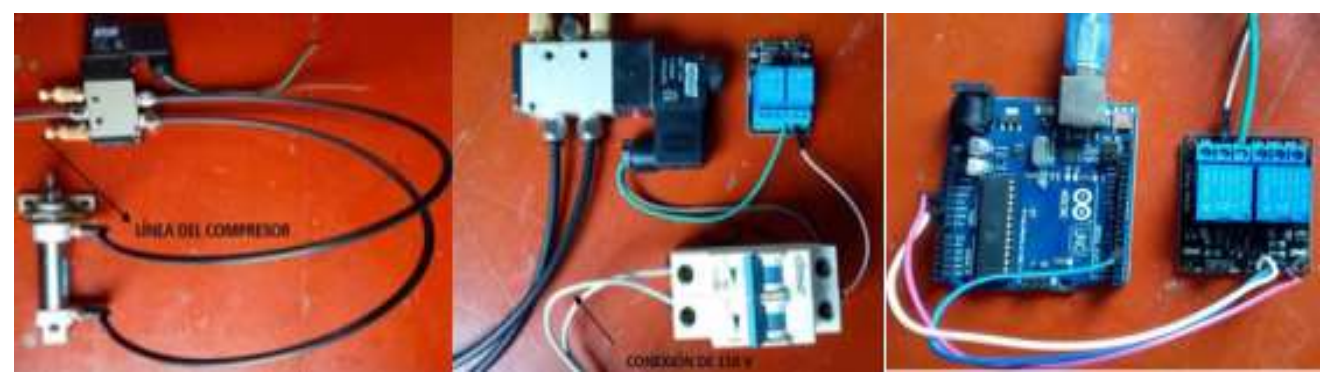

\section{Machine Vision and Artificial Intelligence Review}

It is the first and fundamental part of this research because from it the necessary knowledge is acquired to obtain the best results in the work. It consisted in the review of different sources of information such as scientific publications, Matlab platforms, books. When analyzing the information investigated, it was concluded that by means of the traditional Matlab method for pattern recognition (images) (Ojeda, 2007) cannot be applied directly because cocoa has different color shades and essential characteristics (Gonzales, 2008). By which use is made of the Artificial Intelligence tool called Machine Learning, which can be found in the Toolbox.

\section{Development of the cocoa grading algorithm}

To explain the development of the application, the Matlab programming code is shown as a first step for training the cocoa classification algorithm through supervised learning. Subsequently, Figure 14 shows the flow diagram of the system, which was used as a guide for the development of the entire cocoa classification part. (Khandani, 2005).

Figure 14. Flow diagram of the classification system

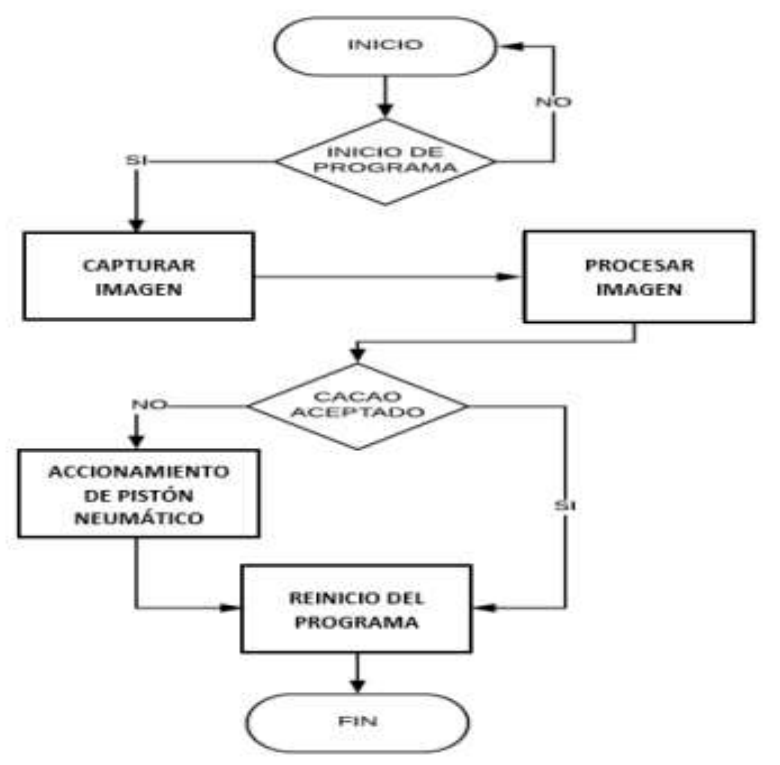




\section{Image Acquisition and Algorithm Training}

The first phase of the process consists of compiling several images of the two categories of cocoa in excellent and poor quality. It should be noted that in this research, the classification will be done through images (Law, 1991). But assimilating to real life this must be executed at the same instant when the product passes through the camera and it detects it and sends the information to Matlab.

Figure 15. Matlab imagedatastore tool.

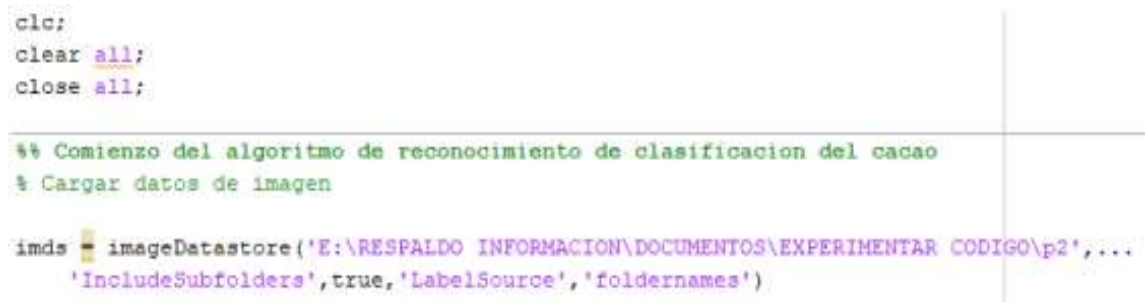

Using the Matlab imageDatastore tool as seen in Figure 6, it has the function to manage a collection of image files using the Excellent and Poor quality categories. Since imageDatastore operates on image file locations and therefore does not load all images into memory, it is safe to use it on large image collections.

In the Figure 16 shows the histogram created in the encoding of the analysis images corresponding to the folders supplied as a basis at the start of programming.

Figure 16. Image analysis. Histogram

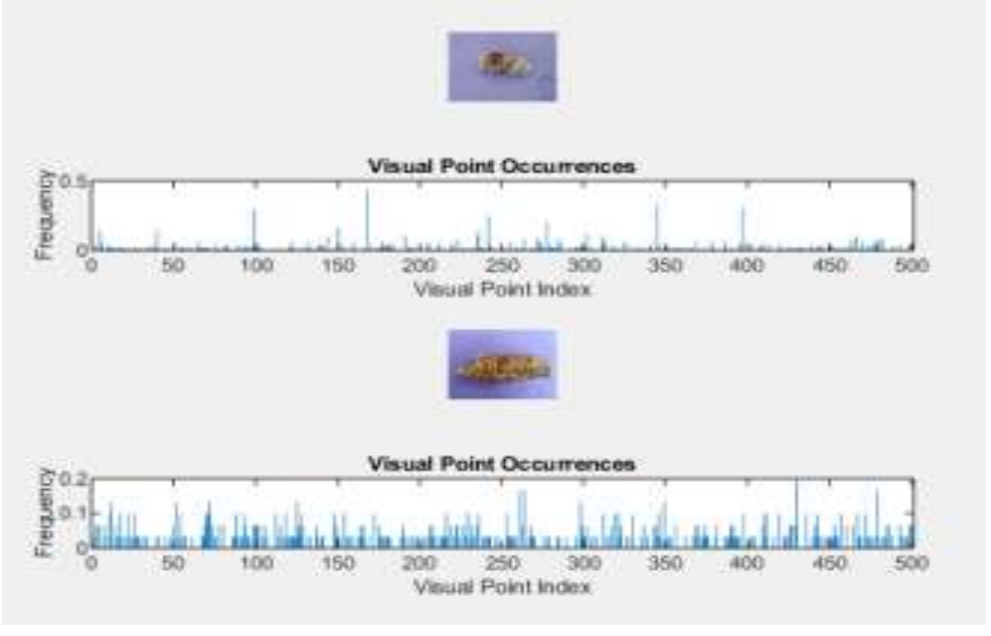

This histogram forms a basis for training the classifier and for actual image classification. In essence, it encodes an image into a feature vector. Accordingly, a table is created using the encoded features from the relevant feature extraction from the images of the two 
analysis categories. Once the necessary information is obtained, the algorithm is trained for image classification, as shown in Figure 17.

Figure 17. Lerner classification - Matlab

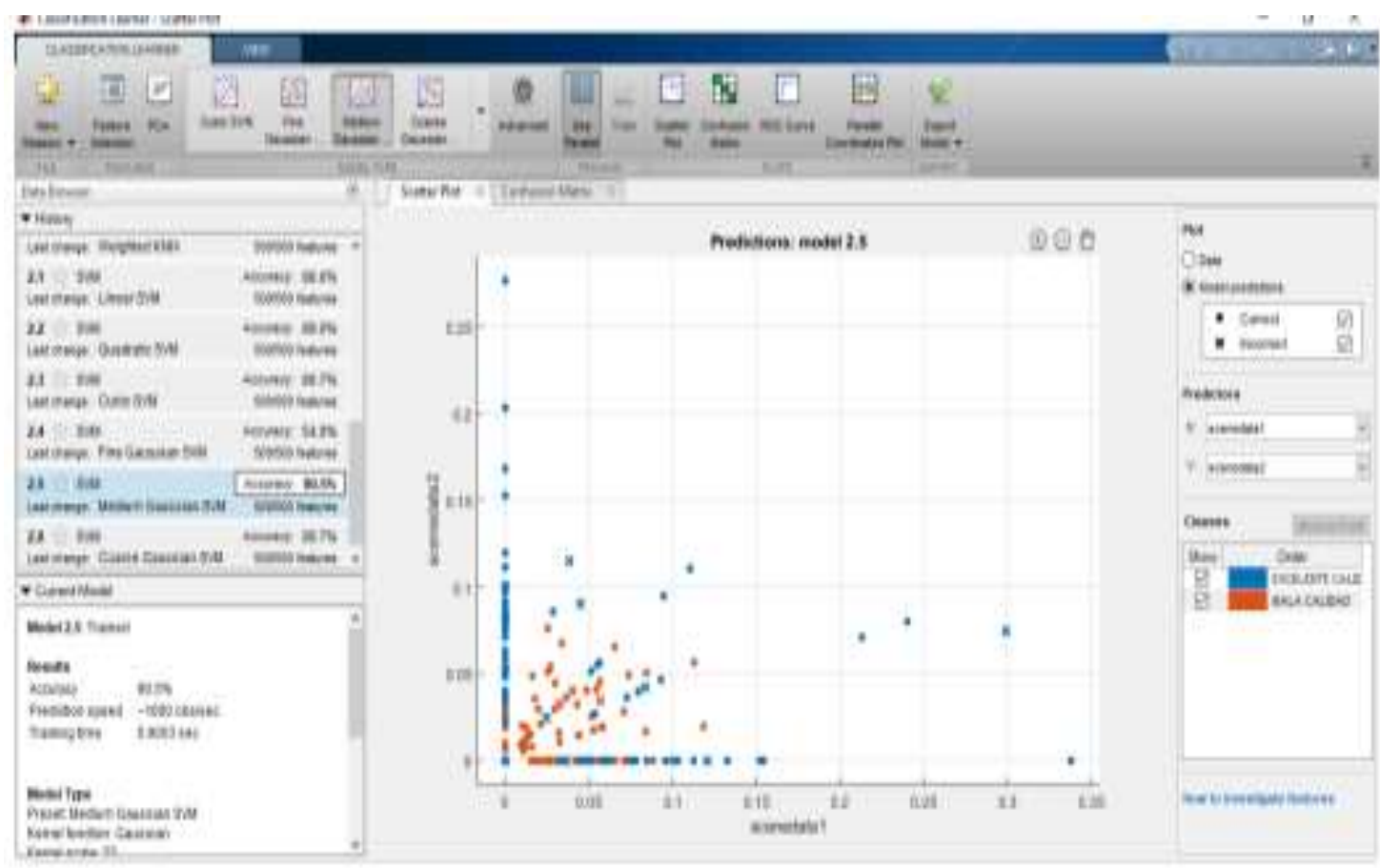

We proceed to select the model with the highest percentage, which corresponds to $90.5 \%$ SVM (Support Vector Machines) Medium Gaussian. This is a set of supervised learning algorithms used for classification and regression. It results in a model that predicts the class of a new sample. This type of classifier provides a fast prediction prediction speed and has a medium level of memory usage which makes it one of the most feasible for our cocoa classification. The scatter plot for the chosen model can be seen in Figure 8, where the misclassified points are shown as an $\mathrm{X}$. This plot helps to investigate the classification characteristics of cocoa. This plot helps to investigate features to include or exclude or as mentioned above allows to visualize training data and misclassified points in the scatter plot. To check the performance per class in the confusion matrix, the diagram that results in the Matlab Classification Learner App application platform is used as shown in the graph below. 
Figure 18. Confusion Matrix

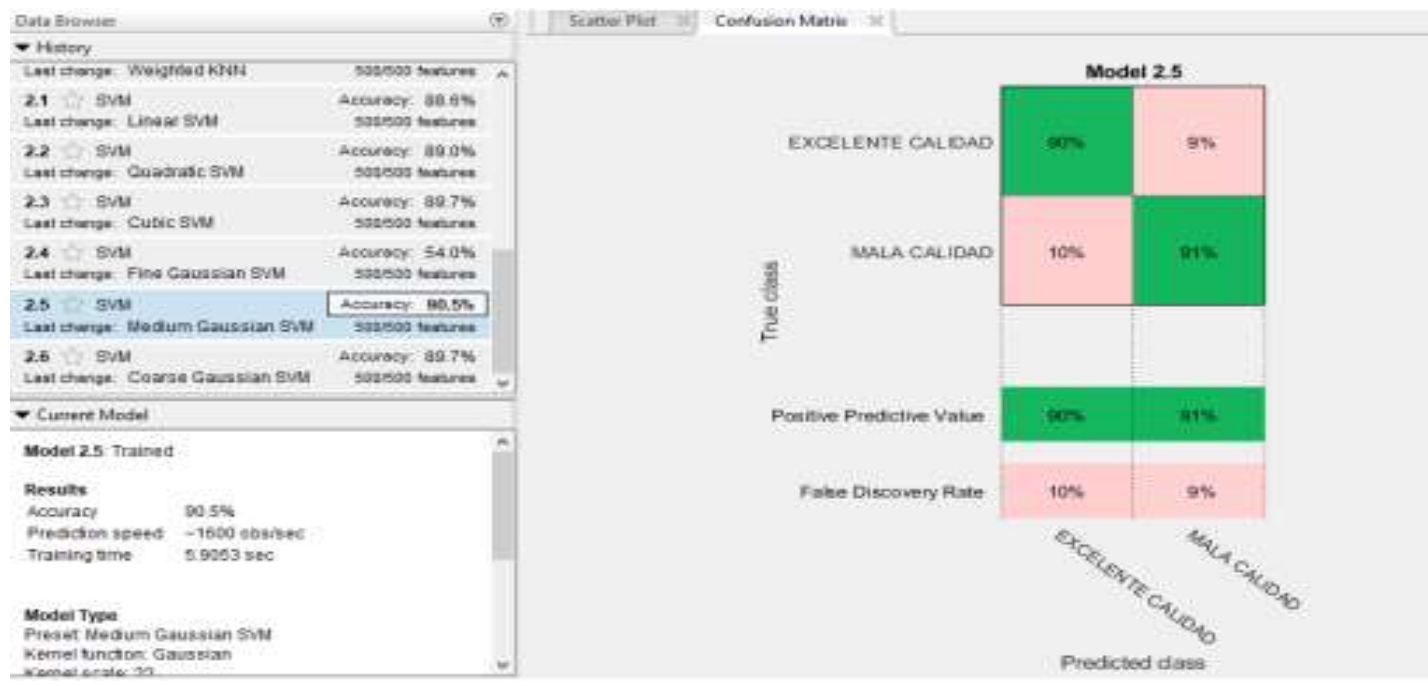

This confusion matrix is used to understand how the currently selected classifier performs in each class, identifying areas where it has performed poorly. This training results in $90 \%$ of cocoa being correctly classified as Excellent quality and $91 \%$ as Poor quality. It can be seen that there are $10 \%$ and $9 \%$ classified incorrectly. Therefore, it turns out that the classification algorithm is efficient for cocoa application with a low level of erroneous data. After creating classification models in "Classification Learner", the model of the classification algorithm is exported and named as desired. The newly created structure appears in the Matlab workspace. This allows to make predictions with new data because it contains a classification object and a function for prediction.

\section{Algorithm testing}

The algorithm is tested using images that were obtained through field research in cocoaproducing farms. The test images are different from those provided in the training process of the intelligent algorithm. The steps followed in this process are detailed below:

1. The test image should be saved in the test folder and create a subfolder in this case it is called SORT. As explained above in the testing phase of the trained algorithm.

2. The test image should be saved in this folder.

Figure 19. Test folder for algorithm training.

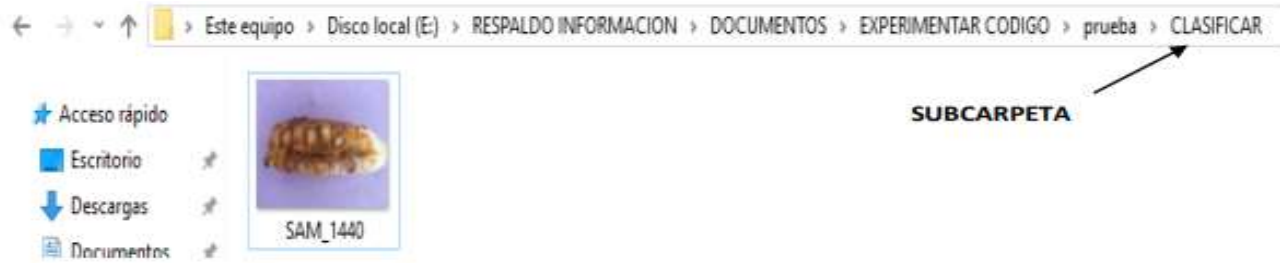


3. Inserted the test image. Open the trained algorithm in Matlab and proceed to click on the RUN button.

Figure 20. Execution of the algorithm

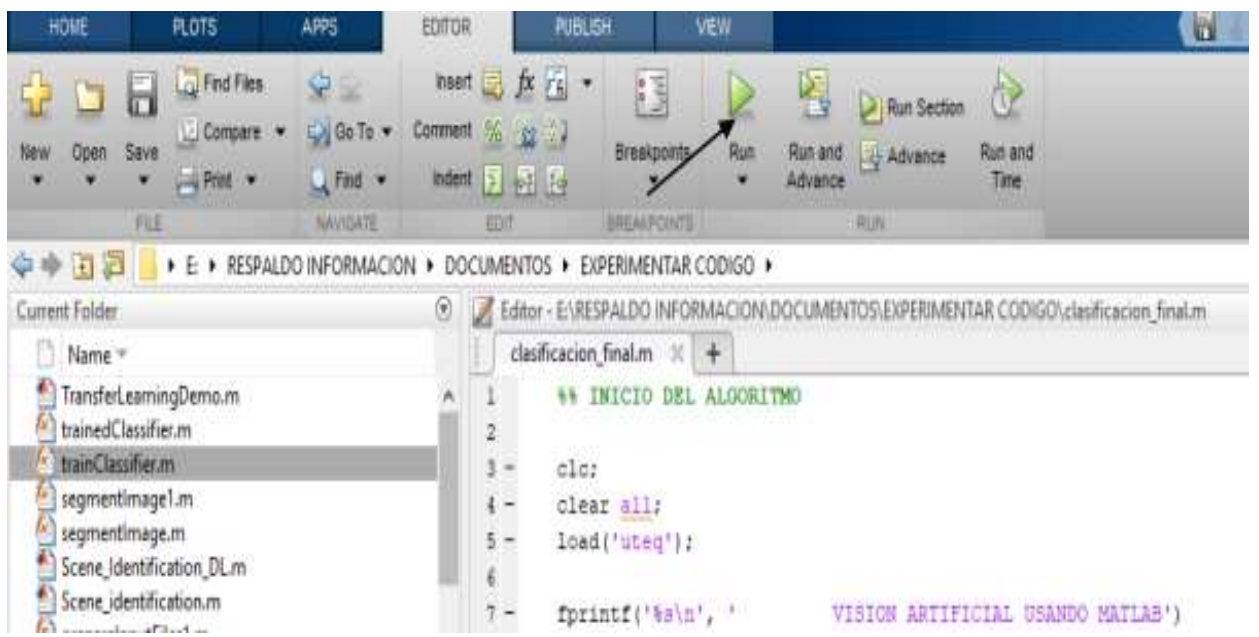

4. Verify the response of the cocoa sorting algorithm.

Figure 21. Verification of algorithm response

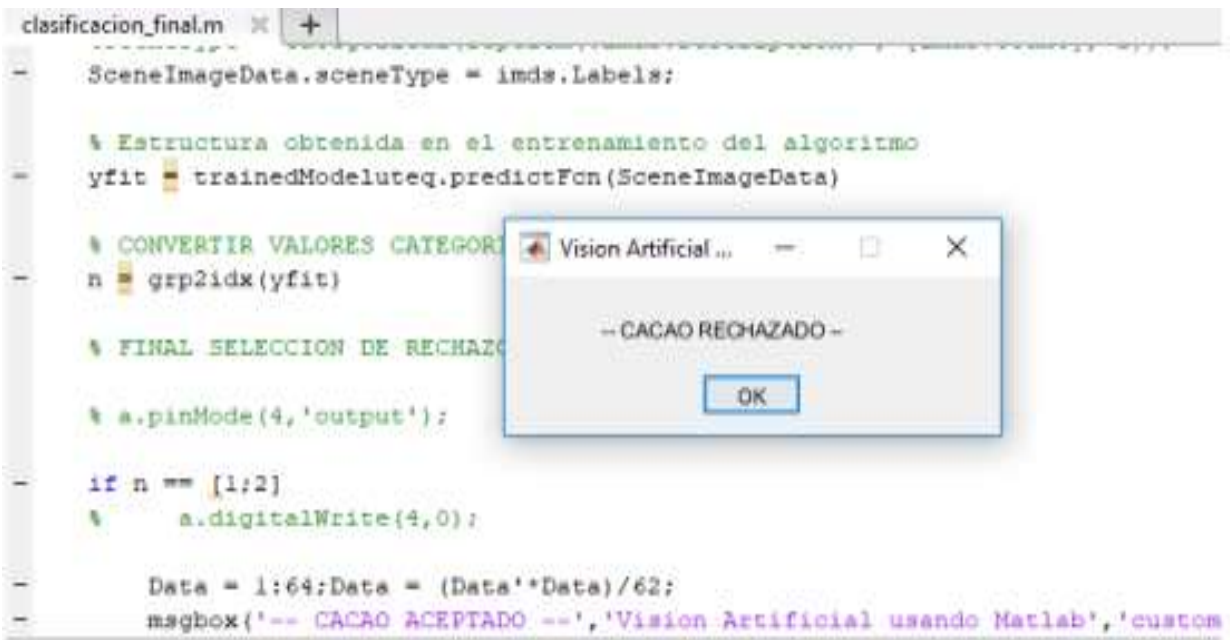

To validate the results, several tests were performed, which are shown in the following figure 22, it can be observed that the algorithm presents an excellent efficiency in the classification of cocoa. As a result, the training was adequate and the development of the intelligent algorithm using Machine Learning in Matlab was completed. 
Figure 22. Tests performed on the trained algorithm

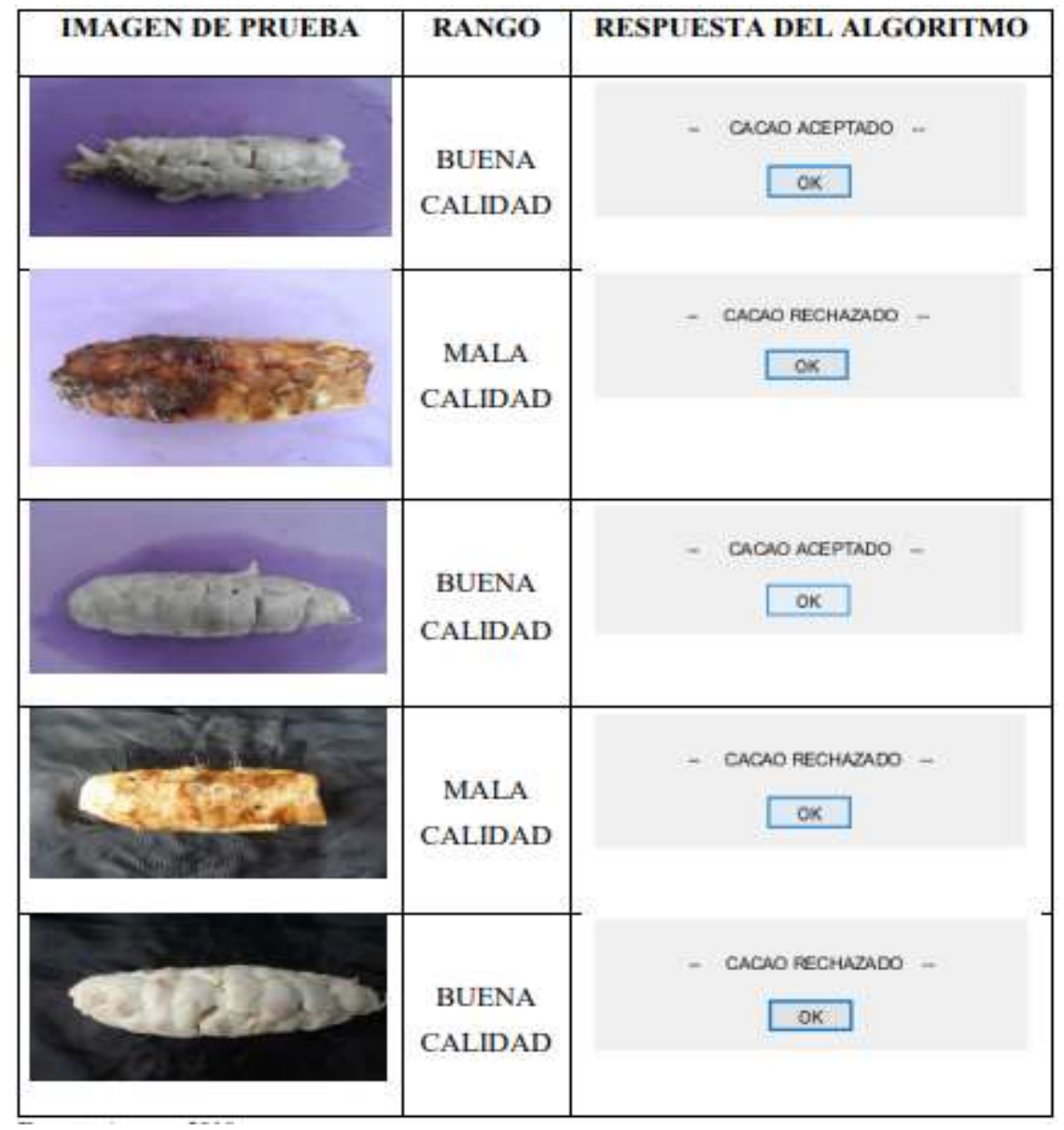

The final part, for the actuation of the piston as shown in figure 23, is based on the use of conditionals where if the trained algorithm when sending the test image detects a cocoa in excellent condition, it sends the signal to the Arduino transformed into numbers, in this case 0 gives the order not to activate, otherwise it sends 1 to activate the piston and reject the product. (Berenguel, 2004).

Figure 23. Piston drive control code

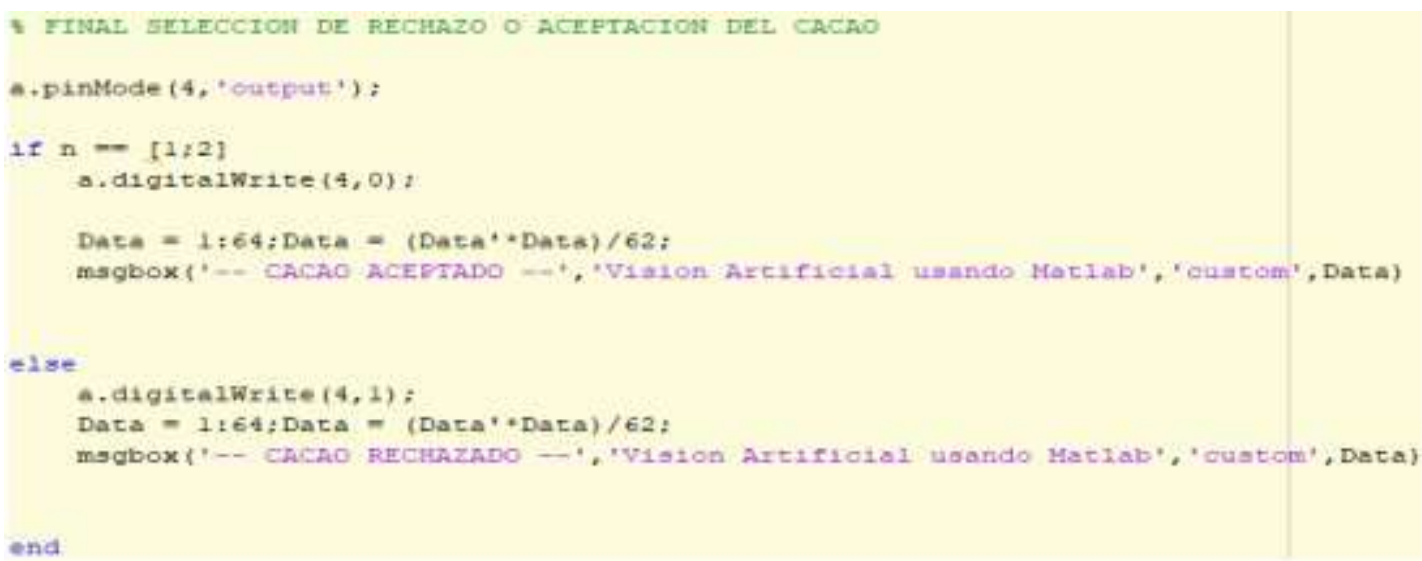




\section{Total cost of machine vision sorting machine and cocoa pulping machine}

In the Table 3 shows the sum of each of the above items to which is also added the value of the design cost and the unforeseen cost, which are those related to transportation, administration and additional costs arising in the development of the project. These are generally equivalent to $5 \%$ of the subtotal costs.

Table 3. Final cost of the machine

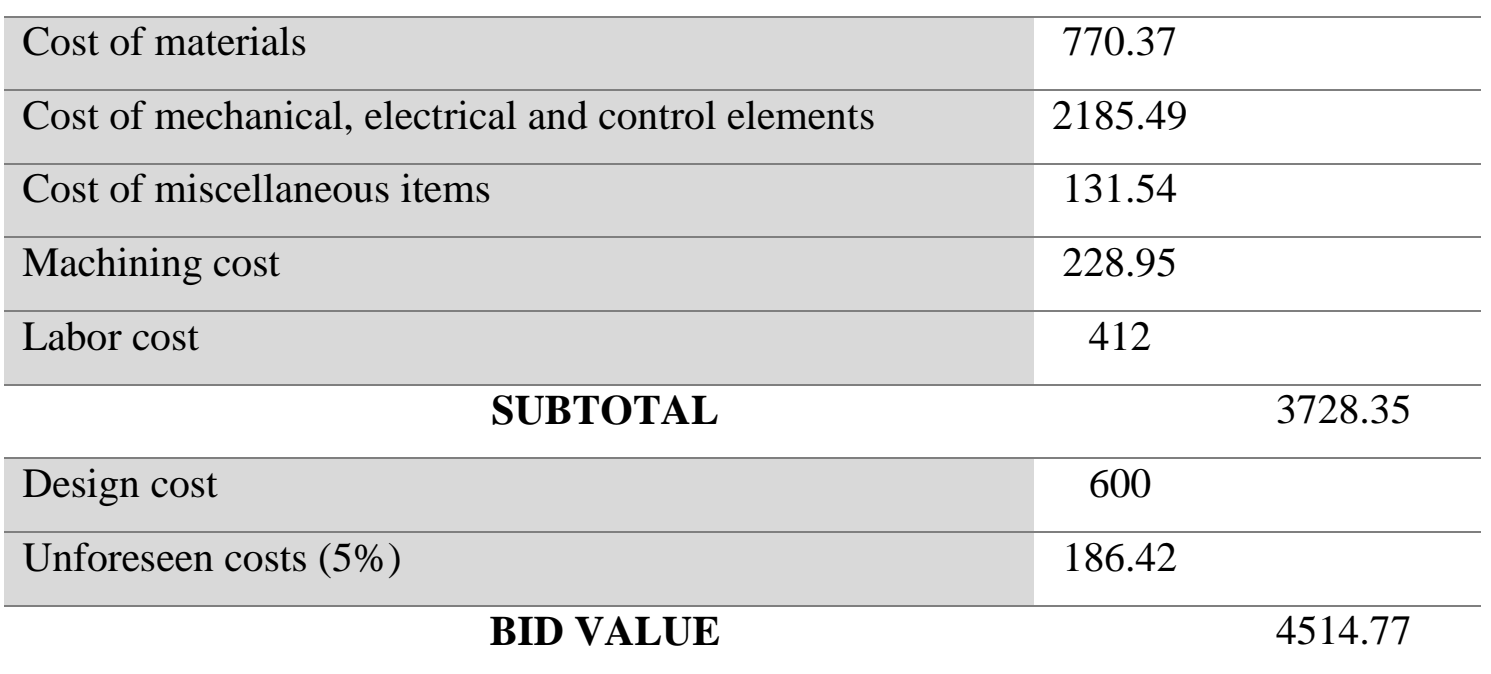

\section{Annual production in a cocoa company}

Cocoa is produced and harvested annually during 3 months with approximately 50 quintals for each month of harvest. The average price per quintal of cocoa during the year is approximately $\$ 90.00$ (Anecacao, 2018). To find the average annual gross income of a cocoa company, the amount of product sold is taken as a reference, as detailed in Table 4. The data was obtained through an interview at the San Antonio farm located in the Buena Fe canton, which has a total of 11 hectares of cocoa plantation.

Table 4. Gross annual income. San Antonio Farm - Buena Fe

\begin{tabular}{lccc}
\multicolumn{1}{c}{ Period } & $\begin{array}{c}\text { Production } \\
\text { quantity }\end{array}$ & Unit value & Total value \\
\hline January - April & 50 Quintals & $\$ 50.00$ & $\$ 4500.00$ \\
\hline May - August & 50 Quintals & $\$ 50.00$ & $\$ 4500.00$ \\
\hline September - December & 50 Quintals & $\$ 50.00$ & $\$ 4500.00$ \\
\hline Total & & & $\$ 13500.00$
\end{tabular}




\section{Amount of production in the company without the machine}

To produce the amount of cocoa pulped during a harvest period (50 quintals in 4 months) 6 workers are needed, who will work for 6 days for a total of 36 days worked in a harvest period. Thus, the annual production costs ( 3 harvesting periods) are detailed in the following table:

Table 5. Annual production cost. San Antonio Farm - Buena Fe

\begin{tabular}{clcc}
\hline Quantity & Description & Unit value & Total value \\
\hline $\mathbf{1 0 8}$ & EMPLOYEE SALARIES & $\$ 15.00$ & $\$ 1620.00$ \\
\hline $\mathbf{1 0 8}$ & EMPLOYEE LUNCH & $\$ 2.50$ & $\$ 270.00$ \\
\hline $\mathbf{3 6}$ & PROTECTIVE GLOVES & $\$ 1.50$ & $\$ 54.00$ \\
\hline & TOTAL & & $\$ 1944.00$ \\
\hline
\end{tabular}

Of the gross annual income (Table 5), 20\% of the company's income is reduced due to plantation maintenance such as fertilization, cultural work, chemical weed control, phytosanitary control, among others (Aguirre, 2015). In this way, Table 6 shows the total costs of the company during its annual production.

Table 6. Total annual cost without machine. San Antonio Farm - Buena Fe

\begin{tabular}{llc}
\hline PRODUCTION COSTS & $\$ 1944.00$ \\
\hline FERTILIZATION, CULTURAL WORK AND CONTROL & $\$ 2700,00$ \\
EXPENSES $(20 \%)$ & $\$ 4644.00$ \\
\hline TOTAL COSTS & \\
\hline
\end{tabular}

After finding the gross income to be produced annually in the cocoa company and the total costs generated, the amount of net production for the production process without the use of the machine is found, obtaining the following result:

Table 7. Amount of net annual production without machine. San Antonio Farm - Buena Fe

\begin{tabular}{ll}
\hline GROSS ANNUAL INCOME & $\$ 13500.00$ \\
\hline TOTAL ANNUAL COST & $\$ 4644,00$ \\
\hline TOTAL COSTS & $\$ 8856.00$ \\
\hline
\end{tabular}

When the cocoa production process is carried out by the manual or common method, the cocoa company receives an annual net income of approximately $\$ 8856.00$. 


\section{Amount of production in the company with the machine}

By acquiring the machine, the cocoa company would need only 2 operators to work during a production period (50 quintals in 4 months), who will work for 2 days for a total of 4 days worked in each harvest period. In this way, production costs will be reduced. Table 8 shows the annual production cost ( 3 harvesting periods):

Table 8. Amount of annual production with machine. San Antonio Farm - Buena Fe

\begin{tabular}{cccc}
\hline QUANTITY & DESCRIPTION & UNIT VALUE & $\begin{array}{c}\text { TOTAL } \\
\text { VALUE }\end{array}$ \\
\hline $\mathbf{1 2}$ & EMPLOYEE SALARIES & $\$ 15.00$ & $\$ 180.00$ \\
$\mathbf{1 2}$ & EMPLOYEE LUNCH & $\$ 2.50$ & $\$ 30.00$ \\
\hline $\mathbf{1 2}$ & PROTECTIVE GLOVES & $\$ 1.50$ & $\$ 18.00$ \\
\hline & TOTAL & & $\$ 228.00$
\end{tabular}

As in the previous situation, the gross annual income is reduced by $20 \%$ due to the aforementioned activities. The total annual cost is detailed in the following table:

Table 9. Total annual cost with machine. San Antonio Farm - Buena Fe

\begin{tabular}{lc}
\hline PRODUCTION COSTS & $\$ 228.00$ \\
\hline FERTILIZATION, CULTURAL WORK AND CONTROL & $\$ 2700,00$ \\
EXPENSES $(20 \%)$ & $\$ 2928.00$ \\
\hline TOTAL COSTS
\end{tabular}

Having found the total costs generated, the net production quantity for the production process with the use of the machine for sorting by artificial vision and cocoa pulper is found, obtaining the following result:

Table 10. Amount of net annual production with machine. San Antonio Farm - Buena Fe

\begin{tabular}{lc}
\hline GROSS ANNUAL INCOME & $\$ 13500.00$ \\
\hline TOTAL ANNUAL COST & $\$ 2928,00$ \\
\hline TOTAL COSTS & $\$ 10572.00$ \\
\hline
\end{tabular}

By carrying out the cocoa production process through the acquisition of the machine, the cocoa company receives an annual net income of approximately $\$ 10572.00$. 
Comparison of the annual income in a cocoa company between manual production and production with the machine vision sorting and cocoa pulping machine

The profit generated by the acquisition of the machine is detailed in the following table:

Table 11. Manual and machine farming. San Antonio Farm - Buena Fe

\begin{tabular}{lc} 
MANUAL PRODUCTION & $\$ 8856.00$ \\
\hline MACHINE PRODUCTION & $\$ 10572,00$ \\
\hline EARNINGS & $\$ 1716.00$ \\
\hline
\end{tabular}

If the results are compared between the annual production value using the common method in the company and the production value with the machine, it is obtained that the cocoa company will annually obtain a total of $\$ 1716.00$ profit in production. The payback time of the amount invested in the machine is:

$$
\begin{gathered}
\text { Time }_{\text {recovery }}=\frac{\text { Total machine cost }}{\text { Net income }} \\
\text { Time }_{\text {recovery }}=\frac{4514,77 \text { dollars }}{1716^{\text {dollars } / \text { year }}} \\
\text { Time }_{\text {recovery }}=2,6 \text { year }
\end{gathered}
$$

So the payback period for the investment in the machine for the company is 2.6 years, after which the farmer begins to make a profit with the use of the pulping machine.

\section{CONCLUSION OR FINAL CONSIDERATIONS}

The most common traditional cocoa pulping processes in the cocoa sector were compared, making an analysis of the pulping time with respect to a product weight of $(32 \mathrm{~kg})$, being the most efficient method of pulping by sieve, taking $29 \mathrm{~s}$, compared to the manual and table pulping processes whose results are 8 and 5 minutes respectively. In this way, the most suitable alternative was selected from among the options proposed by means of weighting criteria, in which the choice of design is based on alternative $\mathrm{C}$, which consists of an artificial vision system for the classification of cocoa, with a sieve type platform that performs a translational movement for the pulping of the almonds, having a weighting result of 0.4525 , much higher than 0.295 and 0.25 corresponding to alternatives $\mathrm{A}$ and $\mathrm{B}$. 
The machine was designed by artificial vision and cocoa pulping machine by applying calculations and design criteria. By means of this, a prototype was generated through the mechanical design software SolidWorks in which each of the main parts was elaborated, as well as the support structure for its subsequent assembly. In the same way, materials and mechanical elements that are available in local markets were selected, thus avoiding the cost increase due to the difficulty in the acquisition. In this way, design errors were corrected and certain components of the machine were optimized to avoid errors in future construction.

To develop the classification system by means of Artificial Vision, the Machine Learning application implemented in the Matlab Toolbox is integrated, where for the extraction of features from the database supplied to the software, the bag of features tool is used, obtaining extraordinary results both in the training and testing parts. The algorithm achieves an excellent product detection rate unlike other algorithms that use auxiliary information such as color, texture, among others. At the same time, the Matlab software is a tool totally friendly with Arduino, which allowed a joint work for the communication between both for the rejection of the defective product by means of the pneumatic pistol in case it detects it in bad condition.

Through the cost analysis of the machine for sorting by artificial vision and cocoa pulping machine, it was detailed that the amount of investment for the manufacture of the machine is $\$ 4255.21$. Similarly, it was determined that a cocoa company whose production is 150 quintals of cocoa pulped annually, will obtain a profit of $\$ 1716.00$ thanks to the reduction of labor and production time, from which it is deduced that the payback period for the investment for the company will be 2.6 years.

\section{LIST OF REFERENCES}

Aguirre, M. M. (2015). El cacao. Orgullosamente Mexicano. Mexico.

Andrade, N. P. (2009). Manual de cultivo de cacao para la Amazonía ecuatoriana. Quito: INIAP.

Anecacao. (2018). Asociacion nacional de exportadores de cacao. Obtenido de http://www.anecacao.com/index.php/es/estadisticas/precios.html

Arduino. (2018). Arduino y Matlab. Obtenido de https://www.arduino.cc/

Barragan, J. C. (2016). Beneficios post-cosecha: Protocolo 5 de mejoramiento de homologacion de los procesos de investigacion en cacao y cafe. Quevedo 
Batista, L. (2009). Guia tecnica del cultivo del cacao. Republica Dominicana: CEDAF; Teofilo Suriel.

Berenguel, M. V. (2004). Introducción a Matlab y su aplicación al Análisis y Control de Sistemas. Sevilla: Escuela Superior de Ingenieros.

Corp, S. (2017). SolidWorks Office Premium 2017. Massachusetts: Solidworks.

Gonzales, R. E. (2008). Digital Image Processing. New York: Pearson Prentice Hall.

Guerra, C. A. (2017). Diseño y construccion de un maquina para la extraccion de la pulpa

Khandani, P. S. (2005). ENGINEERING DESIGN PROCESS. EEUU: Permission.

Krieger, G. y. (2019). Accident Prevention Manual for Business and Industry: Engineering and Technology. Illinois: National Safety Council, Decimoprimera Edicion.

Law, W. D. (1991). Simulation Modeling and Analysis. New York: McGRAW - HILL.

Marshek, R. C. (2013). Diseño de elementos de máquinas. New York: Limusa Wiley.

mathworks. (2018). MATLAB Y SUS APLICACIONES. Obtenido de https://la.mathworks.com/

Nisbett, R. G. (2008). Diseño en Ingeniería Mecánica. NEW YORK: McGRAWHILL/INTERAMERICANA.

Norton, R. L. (2009). Diseño de Maquinaria. NEW YORK: McGRAWHILL/INTERAMERICANA.

Ojeda, L. R. (2007). MATLAB CONCEPTOS BÁSICOS Y PROGRAMACIÓN. Guayaquil: Escuela Superior del Litoral.

PINHALENSE. (3 de 10 de 2018). Obtenido de https://www.pinhalense.com.br/

Profesional, S. d. (2012). Aplicación práctica de la visión artificial en el control de los procesos industriales. España: Proyectos de innovacion aplicada y transferencia del. 